\title{
Relationships between Parental Attachment, Peer Attachment and Stress among School-going Adolescents in Akwa Ibom State Nigeria
}

Edidiong Maurice Abia, Muslihah Hasbullah, Mohd Najmi Daud

To Link this Article: http://dx.doi.org/10.6007/IJARBSS/v12-i1/12171

DOI:10.6007/IJARBSS/v12-i1/12171

Received: 04 November 2021, Revised: 08 December 2021, Accepted: 30 December 2021

Published Online: 19 January 2022

In-Text Citation: (Abia et al., 2022)

To Cite this Article: Abia, E. M., Hasbullah, M., \& Daud, M. N. (2022). Relationships between Parental Attachment, Peer Attachment and Stress among School-going Adolescents in Akwa Ibom State Nigeria. International Journal of Academic Research in Business and Social Sciences, 12(1), 2127-2137.

Copyright: (c) 2022 The Author(s)

Published by Human Resource Management Academic Research Society (www.hrmars.com)

This article is published under the Creative Commons Attribution (CC BY 4.0) license. Anyone may reproduce, distribute, translate and create derivative works of this article (for both commercial and non0-commercial purposes), subject to full attribution to the original publication and authors. The full terms of this license may be seen

at: http://creativecommons.org/licences/by/4.0/legalcode

Vol. 12, No. 1, 2022, Pg. 2127- 2137

Full Terms \& Conditions of access and use can be found at http://hrmars.com/index.php/pages/detail/publication-ethics 


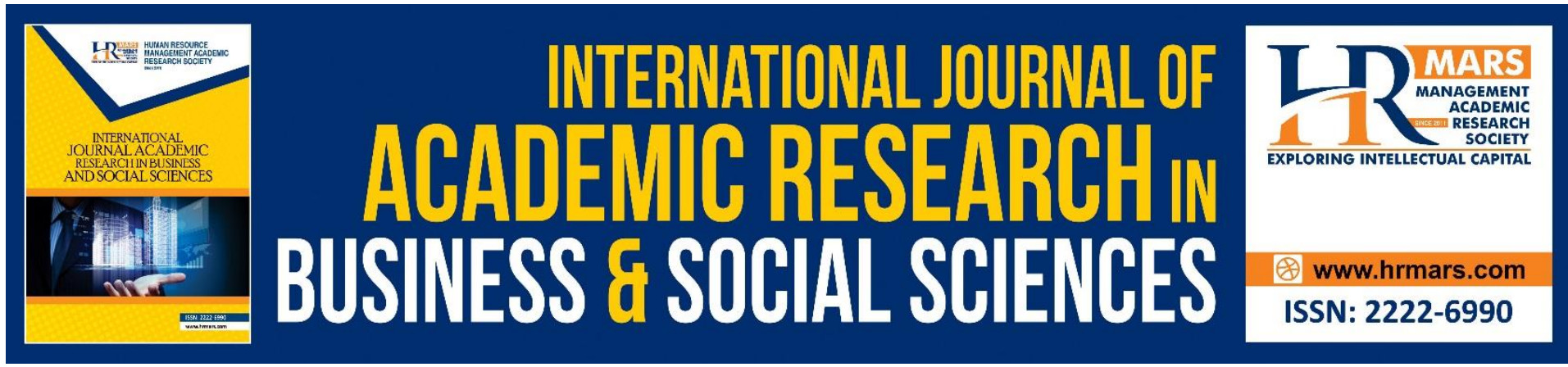

\title{
Relationships between Parental Attachment, Peer Attachment and Stress among School-going Adolescents in Akwa Ibom State Nigeria
}

\author{
Edidiong Maurice Abia, Muslihah Hasbullah, Mohd Najmi Daud \\ Department of Human Development \& Family Studies, Faculty of Human Ecology, Universiti \\ Putra Malaysia, 43400, UPM Serdang, Selangor, Malaysia \\ Email: abicotantalizing2004@yahoo.com
}

\begin{abstract}
Parent-adolescent relationship has been viewed as a crucial factor in the outcome of stress among adolescents. In addition to the stressors in home environment, school-going adolescents spend most of their waking hours within the school environment which also potentially contribute to stress. Empirical investigation has been very scanty with regards to the relationships among stress, parental and peer attachments among school-going adolescents in Nigeria. This study was a cross-sectional survey which drew participants, using a stratified random sampling technique, from three senatorial zones of Akwa Ibom state in Nigeria. Data were collected using a standardized, reliable and valid measures of the study variables among the 372 school-going adolescents. Results showed that parental attachment $(r=-.107, p<.05)$ and peer attachment $(r=-.190 ; p<.01)$ were significantly associated with stress. Results also indicated that parental attachment and peer attachment, significantly predicted stress. Peer attachment was found to be the strongest predictor of stress $(\beta=-.24$, $p<.01)$. Practically, the study offered parents/guardians, home managers and educational institutions useful suggestions on reducing and mitigating the effects of stress. Stress reduction through healthy parental and peer attachment can be enhanced by organizing school-based psycho-educational with focus on parental and peer attachment.
\end{abstract}

Keyword: Parental Attachment, Peer Attachment, Stress, Adolescents.

\section{Introduction}

Adolescence is a period when individuals strive to become independent from their parents. The period of adolescence has been tagged "a period of stress and storm" (Hurlock, 1981), as the adolescent undergoes a myriad of physical and psychological vicissitudes during this period (Abolarin, 2010). The adolescence period is a transitional period of physical and psychological development, which is associated with the teenage years and characterized by conflicts and stress (Obiunu, 2015). While going through this evolution period, adolescents are mostly engulfed by psychosocial problems such as difficulties associated with peer attachment, stress, and parental attachment. Due to adolescents' level of curiosity in their quest for independence and social importance, some of them end up contradicting the whims 
of their parents, peers and social groups by either involving in substance abuse, conduct disorders or educational difficulties (Burke \& Arslan, 2020; Sigfusdottir et al., 2017).

Since school-going adolescents spend most of their waking hours within the school environment or engaged in school-related activities, the potentials for stress are perhaps considerably higher because, in addition to the stressors in home environment, they have to grapple with school environment stressors such as academic difficulties, tests and examinations, possible bullying, and lack of adequate support from teachers and other students. Studies have shown high prevalence of psychosocial problems in adolescents (Jorm et al., 2010; Gilbert 2006). It is also reported that about $10 \%$ to $25 \%$ of adolescents experience psychosocial problems or mental distress during adolescence (Ahmad et al., 2007; Gilbert, 2006).

Stress is real and constitutes part of adolescents' developmental uncertainties. Looking at the various progressions of human revolution and adaptation to development, it is likely for an adolescents will be stressful and be exposed to dangerous situations within this period of transformation (Tricoli and Lipp, 2011; Justo and Lipp, 2010). Stress is a contextual phenomenon that involves a transaction between the characteristics of the person and the environment (Folkman, 2013). Stress can change with time, maybe as a result of how a person can handle the situations that brought about a stressful situation. Kristensen, Schaefer and Busnello (2010) argue that stress develops when the burdens of certain circumstances are perceived as being above the means available to overcome them, resulting in the individual incapable to fight and generate approaches to tackle them. This emphasizes the pivotal role of adolescents' abilities and/or strategies with environment which they require in order to ensure a positive transitional development devoid of behavioral or well-being impairment.

According to Bowlby's Attachment Theory (AT), attachment is a psychological connection which exist within humans and that can persist for a long period of time (Bowlby, 1982). Going by Bowlby's assertion, attachments with parents and peers can significantly ameliorate the level of stress. Several studies (e.g.: Howard and Medway, 2004; Compas, Malcarne, and Fondacaro, 1988) showed attachments and relationships that may be important in giving adolescent a good knowledge on how adolescents can cope with stress in their lives Adolescents as a matter of fact believe that having link or being attached to parents and peers will make them more resourceful in stressful situations. As such, parent-adolescent relationship has been viewed as a critical and crucial factor in the experience and outcome of stress among adolescents (Garbe et al., 2020; Rabbani et al., 2014; Operario et al., 2006). Studies have consistently shown that adolescents who have safe attachments with their parents are more adjustable and experience low stress compared to those without such attachments (Hampel \& Petermann, 2006; Howard \& Medway, 2004). In addition, Lazarus and Folkman (1984) emphasized on perception of the ability to cope with threat, implying that presence of resources such as parental and peer support through healthy attachment will yield a positive outcome. This makes parents and peers some of the most influential and powerful agents in the life of adolescents.

\section{Parental Attachment and Stress}

Studies have shown that significant relationship exists between parental attachment and stress (see: Rabbani, 2015; Li, 2008; Petroff, 2008; McCarthy, Moller \& Fouladi, 2001). As such, 
adolescents with strong or secure parental attachment tend to be more resilient to stress. According to Armsden and Greenberg (1987), adolescents with safe parental connection are more positioned to improve and keep positive relationships, and are able to take care of dangerous or stressful circumstances. It is believed that adolescent whose secure attachments are higher will experience minimized stress. In line with this notion, studies evaluating the relationship between parental attachment and stress found that adolescents that have a good and safe connections to parents account lower observed stress (Howard \& Medway, 2004; Kenny \& Rice, 1995). This further implies that adolescents' ability to cope with or manage stress is affected by parental attachment. Thus, the younger adults are securely attached to their parents, the greater their chances of overcoming stressful situations. This is evidenced in adolescents' low level of handling unfamiliar situations which according to Armsden and Greenberg (1987) could be enhanced by secure parental attachment.

Interestingly, adolescents with high levels of stress-free lives are fond of their parents. This is undoubtedly the rationale behind a report from McCarthy et al (2001) study revealed that students that account high levels of attachment to parents are least expected to account high levels of stress. Attachment relationship is the basis of the attachment system, which is revolved when people encounter stress (Bernier, Larose, Boivin, and Soucy, 2004). During stressful situation, adolescents with safe attachments perceived their selves as closer and more susceptible to others; they understand stress as mind and thoughts infuriating, instead of threatening. Prior to such situations', securely attached adolescents are better prepared by their parents for such encounter and other unfamiliar contexts, which aggravate stress (Rabbani, Kasmaienezhadfard and Pourrajab, 2014). As a result of this, adolescents with strong parental attachment are equipped with cognitive skills of stress evaluation and management. Hence, the stronger the connection adolescents have with their parent, the less stress and more adjustment tendencies (Mattanah et al., 2011).

\section{Peer Attachments and Stress}

Attachment dynamics have been explored in different contexts and across a spectrum of age ranges (Howard and Medway, 2004). Safe connections are linked to self-assurance, healthy modification, and positive life transitions (Paterson, Field \& Pryor, 1995). Insecure attachment is associated with anxiety, stress, personality disorders, marital distress, and suicidal thoughts (DiFilippo and Overholser, 2000; Papini and Roggman, 1992). Infants move to adolescent stage of life, peer value as a source of alliance and intimacy increases (Rabbani, 2015). Despite parents serving as original learning source to adolescents on proper way of behavior and meeting individual need, adolescents highly explore peers' relationships to solidify what they learned from their parents (Riggs, 2013). By so doing, stressful situations are subdued by adolescents due to peer encouragements and support.

While adolescents with less peer attachment could regularly be victimized by stress, those with secure attachment with their peers is believed to receive precautionary advices from their peers and thus not afraid of contextual stress situations. For instance, female adolescents often educate their female peers on possible ways to prevent unwanted pregnancy, while males inform their adolescent peers on the dangers of substance use. All things being equal, whereby an adolescent that belongs to any of the above peers encounters such stressful situation, his/her peer instruction will help him/her out of such stress. Given inevitable occurrence of stress among adolescents, peer attachment is positioned to foster 
fast decline of stress symptoms and stress-produced emotions within and around adolescents. For instance, if students in a college do not like to mingle with other student to do class work and other group studies, he/she might likely have a less academic performance and earn less grade and complete assignments and course works successfully than peer attached students (Petroff, 2008). Thus, adolescents' academic stress could be averted with peer attachment and continuous group reading/presentations. It is often reported that first year college students are stressed as they relocate to new environment which is likely far from their family members. Petroff (2008) asserted that with secure peer attachment, adolescents (students) would easily adapt to the rigors of college courses and life. Hence, peer attachment serves as a galvanizing mechanism towards stress among adolescents.

Despite a plethora of studies that investigated stress among school-going adolescents (e.g., Arhin et al., 2019; Everly \& Lating, 2019; Rabbani et al., 2014; Momtazi \& Rawson, 2010; Terry et al., 1995), there exists a range of uninvestigated tasks in connection with these variables in different geographical locations and contexts. As observed by Rabbani et al. (2014), although quite a lot is known about the effects of stress, there are still major gaps, especially in relation to the association between stress, peer and parental attachment which is especially the case in Akwa Ibom state, Nigeria, where empirical findings in this regard are very scanty. Thus, the general objective of this study is to determine the relationship between parental attachment, peer attachment and stress and to determine the predictors of stress among school-going adolescents in Akwa Ibom state, Nigeria.

\section{Methods}

\section{Designs, Location and Sampling}

The study employed a quantitative approach. Quantitative study allows the generalization of inferences from a study sample to a larger population (Neuman, 2006; Creswell, 2003), thereby saving time. The study employed a stratified sampling technique and upon stratification of the subjects, randomization was further utilized to select the respondents. The study was conducted in three major towns of Akwa Ibom State - Ikot Ekpene, Oron and Uyo. Akwa Ibom state is one of the 36 states of Nigeria and Federal Capital Territory (FCT). The State is located in the Southern part of Nigeria, and geo-politically in the South-south region of Nigeria consisting of Akwa Ibom, Bayelsa, Cross River, Delta, Edo and Rivers states.

\section{Data Collection}

Data were collected through survey with the use of self-administered questionnaires. The respondents were made to understand that any information retrieved from them should be anonymized. At the data collection point, only adolescents between the ages of 10 and 19 were handed in questionnaires to input their views. Data were therefore collected stratified at three (3) different places (Ikot-Ekpene, Oron, and Uyo) in Akwa-Ibom state of Nigeria.

\section{Research Instruments}

The study instrument was a structured questionnaire, which comprised of closed-ended questions and tabulated statements that sought respondents' opinion on parental attachment, peer attachment and stress. 


\section{Parental Attachment and Peer Attachment}

Parental attachment and peer attachment were measured using the Parents and Peer Attachments (IPPA) developed by Armsden and Greenberg (1987). The scale on parental attachment assessed adolescents' perceptions of relationships with their parents, particularly how well these the parental figures serve as sources of psychological security. Whereas the scale for peer attachment assessed adolescents' perceptions of relationships with their close friends, particularly how well their peers serve as sources of psychological security. The higher the scores for both scales depict the greater attachment with parents and peers. There were 28-item for parental attachment scale and 25 -item for peer attachment scale on a five-point Likert-scale response format ( $1=$ Never True, $2=$ Not Very Often True, 3= Some-times True, 4= Often True, and 5= Always True). The Cronbach's alpha coefficient of the IPPA scales for parental attachment was 0.710 and 0.759 for peer attachment on the actual study.

\section{Stress}

The Depression, Anxiety and Stress Scale (DASS-21) developed by Lovibond and Lovibond (1995) is a set of three self-report scales designed to measure the negative emotional states of depression, anxiety and stress. Based on the purpose of this study, only the Stress subscale was used. It measures levels of chronic non-specific arousal such as difficulty relaxing, nervous arousal, and being easily upset/agitated, irritable/over-reactive and impatient. High scores on the Stress subscale indicate high adolescent stress experience. Respondents were asked to rate the extent to which they had experienced stress over the past week using a 5-point severity/frequency Likert-formatted scale ranging from 1 (Did not apply to me at all), 2 (Somehow applied to me), 3 (Applied to me to some degree, or some of the time), 4 (Applied to me to a considerable degree, or a good part of time) to 5 (Applied to me very much, or most of the time). The Cronbach's alpha coefficient of the Stress subscale was 0.756 on the actual study.

\section{Data Analysis}

The study used statistical package for social sciences (SPSS) version 25 to analyze the data. Descriptive statistics (frequency, percentage, mean and standard deviation) were used for describing the demographic characteristics. Pearson correlation test was used to determine the relationship between parental attachment, peer attachment and stress. More so, standard multiple linear regression was used to test the predictive effects of parental attachment and peer attachment on stress.

\section{Results and Discussion}

The respondents' demographic characteristics has been summarized in Table 1. Result shows that out of the overall sample size (372), more than half of the respondents (221), which constitute $(59.4 \%)$, are females, while the remaining $(40.6 \%)$ are males. Respondents within the ages of 13 and 15 years accounted for more than half of the respondents as they comprise of $(53.5 \%)$, followed by respondents between the ages of 16 and 18 years which accounted for $37.1 \%$, whereas respondents between 10 and 12 years constitutes of $9.4 \%$. All respondents of the study are secondary school-going students. In terms of religion, majority respondents were Christians (99.5\%) and only two respondents identified themselves with a different faith. 
Table.1 : Respondent's Demographic Characteristics ( $\mathbf{~ = ~ 3 7 2 ) ~}$

\begin{tabular}{|c|c|c|c|c|c|}
\hline Variable & & $\mathbf{n}$ & $\%$ & Mean & SD \\
\hline \multicolumn{6}{|l|}{ Gender } \\
\hline & Male & 151 & 40.6 & & \\
\hline & Female & 221 & 59.4 & & \\
\hline \multicolumn{6}{|l|}{ Age } \\
\hline & $10-12$ years old & 35 & 9.4 & & \\
\hline & 13-15 years old & 199 & 53.5 & 14 & 3.97 \\
\hline & $16-18$ years old & 138 & 37.1 & & \\
\hline \multicolumn{6}{|c|}{ Education level } \\
\hline & Secondary school & 372 & 100 & & \\
\hline \multicolumn{6}{|l|}{ Religion } \\
\hline & Christianity & 370 & 99.5 & & \\
\hline & Others & 2 & .5 & & \\
\hline
\end{tabular}

Note: $S D=$ Standard Deviation

\section{Relationships between Parental Attachment, Peer Attachment, and Stress}

The relationships between parental attachment, peer attachment and stress among the respondents were examined using the Pearson product-moment correlation coefficient. Primary analyses were executed to make sure no violation of the assumptions of normality, linearity and homoscedasticity. In addition, ensuing results are based on Cohen (1988), which suggested that a correlation coefficient of .10 indicates small correlation; .30 indicates moderate correlation; and .50 indicates large correlation.

The investigation (Table 2) found a negative significant small correlation between parental attachment and stress among the respondents $(r=-.107, p<.05)$ which means that parental attachment is negatively and marginally related to stress among the respondents. This depicts a meager confidence in the relationship between these two variables and those high levels of parental attachment tend to trigger low stress. This result is in tandem with the findings of Rabbani (2015) and Petroff (2008) who found a negative significant relationship between parental attachment and stress. This finding could be as a result of Nigerian adolescents' secure attachment to their parents, which emboldens them in any unfamiliar or stressful situations. This finding is consistent with previous empirical evidence (Alharbi et al., 2019; Arhin et al., 2019) supporting the notion that parental attachment is inversely related to stress among young people.

Table 2: Relationships between Parental Attachments, Peer Attachment, and Stress ( $\mathrm{n}=$ 372)

\begin{tabular}{llll}
\hline Variables & \multicolumn{3}{c}{ Stress } \\
\cline { 2 - 4 } & \multicolumn{3}{c}{$\mathrm{r}$} \\
\hline Parental attachment & -.107 & & $<.05$ \\
Peer Attachment & -.190 & & $<.001$ \\
\hline \multicolumn{1}{c}{ Note: $p<.05 ; p<.001$} & &
\end{tabular}

An investigation into the relationship between peer attachment and stress (Table 2) also found a negative significant small correlation between peer attachment and stress among the 
respondents $(r=-.190, p<.001)$, with high levels of peer attachment associated with low stress. In other words, the more adolescents are attached to their peers, the less they are engulfed with stressful situations. This is an indication that adolescents with quality peer relationships are likely to express their emotions, thoughts, and difficulties openly within their groups, and as a result enable them to ameliorate their stress levels through exchange of views among peers. This finding is in tandem with Rabbani (2015) and Mota and Matos (2013) who found that peers tend to be an important source of support in managing their stress. Given this, Nigerian school going adolescents tend to experience low stress if they are strongly attached to their peers.

\section{Predictive Effects of Parental and Peer attachments on Stress}

Standard multiple linear regressions were conducted to determine the predictive effects of parental attachment and peer attachment on Nigerian adolescents' stress. Preliminary analyses were conducted to ensure no violation of the assumptions of normality, linearity, multicollinearity and homoscedasticity.

Parental attachment and peer attachment were entered as independent variables into the regression model and the entire model was statistically significant. The model explained $4 \%$ of the variance in stress $(F=6.653, p=.001)$, with peer attachment recording higher beta value $(\beta=-.24, p<.01)$ as depicted in Table 3 below. This result is an indication that in spite of Nigerian adolescents' high peer attachment levels as evidenced in the present study, other factors are eminent in significant prediction of their stressful situations. Adolescents' attachment styles enable them to react constructively towards stress (Petroff, 2008); however, insecure attachment does not affect stress. Given Nigerian adolescents' high parental attachment level which could not predict stress; the study concludes that their attachments are insecure, implying that they tend to internalize withdrawal behaviors in the event of stressful situations (Ainsworth, Blehar, Waters, and Wall, 1978).

Table 3: Effects of Parental Attachment, Peer Attachment on Stress

\begin{tabular}{lllllll}
\hline Variables & B & SE & Beta & t & $\boldsymbol{p}$-value & VIF \\
\hline Constant & 11.407 & 2.424 & & 4.707 & .000 & \\
$\begin{array}{l}\text { Parental } \\
\text { attachment }\end{array}$ & .005 & .023 & -.12 & .214 & .831 & 1.189 \\
$\begin{array}{l}\text { Peer } \\
\text { attachment }\end{array}$ & .054 & .023 & -.24 & 2.372 & .018 & 1.194
\end{tabular}

$\mathrm{R}^{2}=.040 ;$ Adjusted $\mathrm{R}^{2}=.033$

Note: $\mathrm{B}=$ Unstandardized beta, $\mathrm{SE}=$ Standard error, $\mathrm{t}=\mathrm{t}$ Statistics, $\mathrm{VIF}=$ Variance inflation factor

The above result substantiates the notion that peer attachment significantly predicts stress among Nigerian adolescents. This finding is in tandem with Rabbani (2015) and Operario, Tschann, Flores, and Bridges (2006) who found that peer attachment predicts stress among adolescents, and that adolescents' behaviors in relation to stress depends on an individual's social background and mainly relationship with peer group and family members. Adolescents are believed to subdue their stress if they have strong or high attachment through interpersonal encouragements and supports from their peers. This in turn validates peer as 
attachment figures (Schnyders, 2012), implying that when adolescents encounter stressful situations, interpersonal encouragements from adolescents' peers strengthen their stress management tendency which stands as a stress management resource for low stress.

\section{Conclusion and Implications}

Studies on the relationships between parental attachment and stress are still insufficient in many countries and cultures (Al-Abhudi, 2019; Ellis et al., 2019; Rabbanit al., 2014) including Nigeria, and the factors that contribute to stress management such as peer attachment and parental attachment (Burke \& Arslan, 2020; Waters, 2019; Waters et al., 2015; Rabbani, 2014) were lack attention in Nigeria. Therefore, in the present study the findings indicated that there is a significant negative relationship between parental attachment and stress as well as there is a significant negative relationship between peer attachment and stress. As such, it can be concluded that the higher the level of parental attachment, the lesser the stress adolescent's encounter. Also, the more adolescents are attached to their peers, the less they are engulfed with stressful situations because when adolescents express their emotions, thoughts, and difficulties openly within their groups, it enables them to reduce their stress levels through exchange of views among peers. Results of standard linear regression indicates that peer attachment independently predict stress $(\beta=-.24 \mathrm{P}<.01)$ among school-going adolescents, where peer attachment explains only about $4 \%$ of the variance in stress. Other more potent variables need to be identified and critically examined in the future research Practically, the study indicates that parents/guardians, home managers and educational institutions need to implement parenting programs to enhance effective parenting styles and to reduce and mitigate the negative effects of peer attachment and stress. Stress reduction through healthy parental and peer attachment can be enhanced by organizing school-based psycho-educational with focus on parental and peer attachment.

It is suggested that future research on the stress among school-going adolescents may include data from other geographical locations in Nigeria and it can be enhanced through multiple methods of investigation such as through parents or peer reports to increase confidence of the findings. Furthermore, the relationships between variables under study be examined using a longitudinal design to enable researchers identify the possible changes on the influence of parental attachment on stress among adolescents over time.

\section{Ethical Clearance}

The Ethical Clearance for this project has been approved by the Ethics Committee for Research Involving Human Subjects UPM (JKEUPM) on 14/02/2019 (JKEUPM-2018-347).

\section{References}

Abolarin, E. E. (2010). Essentials of developmental psychology. Abuja: Petra Digital Press.

Ahmad, A., Khalique, N., Khan, Z., Amir, A. (2007). Prevalence of psychosocial problems among school going male adolescents. Indian Journal of Community Medicine,32 (3); pp. 219221.

Ainsworth, M. D. S. (1989). Attachments beyond infancy. American Psychologist, 44, pp. 709716.

Alharbi, A., Alsuhaibani, K., Almarshad, A., \& Alyahya, A. (2019). Depression and anxiety among high school student at Qassim region. Journal of Family Medicine and Primary Care, 8 (2), 504-510. 
Arhin, D. K., Asante, K. O., Kugbey, N., \& Oti-Boadi, M. (2019). The relationship between psychological distress and bullying victimisation among school-going adolescents in Ghana: a cross-sectional study. BMC Research Notes, 12(1), $264-271$.

Armsden, G. C., \& Greenberg, M. T. (1987). The inventory of parent and peer attachment: Individual differences and their relationship to psychological well- being in adolescence. Journal of Youth and Adolescence, 16, (5), 427-454.

Bernier, A., Larose, S., Boivin, M., \& Soucy, N. (2004). Attachment state of mind: Implications for adjustment to college. Journal of Adolescent Research, 19, (6), 783-806.

Bowlby, J. (1982). Attachment and loss: Retrospect and Prospect. American journal of Orthopsychiatry, 52, (4), 664-678.

Burke, J., \& Arslan, G. (2020). Positive education and positive school psychology during COVID19 pandemic. Journal of Positive School Psychology, 4, 137-139.

Cohen, J. (1988). Statistical Power Analysis for the Behavioral Sciences (2nd ed.). Hillsdale, NJ: Lawrence Erlbaum Associates, Publishers.

Compas, B. E., Malcarne, V. L., \& Fondacaro, K. M. (1988). Coping with stressful events in older children and young adolescents. Journal of Consulting and Clinical Psychology, 56(3), 405-411. https://doi.org/10.1037/0022-006X.56.3.405.

Creswell, J. W. (2003). Research design: qualitative, quantitative, and mixed approaches (2nd Ed.). Thousand Oaks, CA: Sage Publications, Inc.

DiFilippo, J. M., \& Overholdser, J. C. (2000). Suicidal ideation in adolescent psychiatric inpatients as associated with depression and attachment relationships. Journal of Clinical Child Psychology, 29, 155-166.

Everly, G. S., \& Lating, J. M. (2019). The concept of stress. A clinical guide to the treatment of the human stress response. New York: Springer.

Folkman, S. (2013). Stress, coping, and hope. In B. I. Carr \& J. Steel (Eds.), Ganste, D. C., \& Victor, B. (1988). The Impact of Social Support on Mental and Physical Health. British Journal of Medical Psychology, 61 (1), 17-36.

Garbe, A., Ogurlu, U., Logan, N., \& Cook, P. (2020). COVID-19 and remote learning: experiences of parents with children during the pandemic. American Journal of Quality Research, 4, 45-65. doi: 10.29333/ajqr/8471

Gilbert, A. (2006). Adolescent care. Canadian Family Physician, 52 (11), 1440-1441.

Hampel, P., \& Petermann, F. (2006) perceived stress, coping and adjustment in Adolescence. Journal of Adolescence Health, 38 (4), 409-415.

Howard, M. S., \& Medeway, F. J. (2004). Adolescents' attachment and coping with stress. Psychology in Schools, 41, (3), pp. 391,402.

Hurlok, E. B. (1981). Developmental psychology a life-span approach (New Delhi: Tata McGraw-Hill Publishing Company Ltd.).

Jorm, A. F., Kitchener, B. A., Sawyer, M. G., Scales, H., \& Cvetkovski, S. (2010). Mental health first aid training for high school teachers: a cluster randomized trial; BMC Psychiatry, 10-51.

Lazarus, R. S., \& Folkman S. (1984). Stress, appraisal, and coping. New York: Springer Publishing Company.

$\mathrm{Li}, \mathrm{M}$. H. (2008). Relationships among stress coping, secure attachment, and the trait of resilience among Taiwanese college students. College Student Journal, 42, (2), pp. 312325. 
Lovibond, P. F., \& Lovibond, S. H. (1995). The structure of negative emotional states: Comparison of the Depression Anxiety Stress Scales (DASS) with the Beck Depression and Anxiety Inventories. Behaviour Research and Therapy, 33, 335-343.

Mattanah, J. F., Lopez, F. G., \& Govern, J. M. (2011). The contributions of parental attachment bonds to college student development and adjustment: A meta-analytic review.

McCarthy, Moller, \& Fouladi. (2001). Continued attachment to parents: Its relationship to affect regulation and perceived stress among college students. Measurement and Evaluation in Counseling and Development; Measurement and Evaluation in Counseling and Development.

Momtazi, S., \& Rawson, R. (2010). Substance Abuse among Iranian high school students. Current opinion in psychiatry, 23, (3), pp. 221-226.

Mota, C. P., \& Matos, P. M. (2013). Peer attachment, coping and self-esteem in institutionalized adolescents: The mediating role of social skills. European Journal of Psychology of Education, 28, 1, 87-100. Digital Object Identifier (DOI) 10.1007/s10212012-0103-z. ISSN: 0256-2928 (Print) 1878-5174 (Online).

Neuman, W. L. (2006). Social research methods: Qualitative and quantitative approaches (6th Ed.) Boston: Allyn and Beacon.

Obiunu, J. J. (2015). Relationship between Parents and Peer Influences on Qualities of Adolescent Friendship. Journal of Education and Practice, 6 (8), 128-133.

Operario, D., Tschann, J., Flores, E., \& Bridges. M. (2006). Brief Report: Associations of parental warmth, peer support, and Gender with Adolescence Emotional Distress. Journal of Adolescence, 29 (2), 299-305. doi: 10.1016/j.adolescence.2005.07.001.

Papini D. R, \& Roggman L. A. (1992). Adolescent perceived attachment to parents in relation to competence, depression and anxiety: A longitudinal study. J Early Adolesc; 12, pp. 420- 40.

Paterson, J. E., Field, J., \& Pryor, J. (1995). Adolescent's perceptions of their attachment relationships with their mothers, fathers, and friends. Journal of Youth and Adolescence, 23, 579-599.

Petroff, L. L. (2008). Stress, adult attachment, and academic success among community college students.

Rabbani, M., Kasmaienezhadfard, S.\& Pourrajab, M. (2014). The Relationship between Parental Attachment and Stress: A Review of Literatures Related to Stress among Students. The Online Journal of Counseling and Education, (1),42-50. Available at: http://www.tojce.com.frontend/articles/pdf/v03i01/Rabbani\%20et\%20al.\%204250.pdf.

Riggs, S. A (2013). Adolescent behavior problems and inter-parental conflicts: The moderating role of parent-child attachment. (PhD Thesis), University of North Texas, United States of America.

Schnyders, C. (2012). Parental and peer attachment as predictors of the perceived experience of emerging adulthood among undergraduates between the ages of 18-20: A multiple regression study (Doctoral dissertation), Kent University, USA.

Sigfusdottir, I. D., Kristjansson, A. L., Thorlindsson, T., \& Allegrante, J. P. (2017). Stress and adolescent well-being: the need for an interdisciplinary framework. Health Promotion International, 32, 1081-1090

Tricoli, V. A. C., \& Lipp, M. E. N. (2011). Escala de Stress para Adolescentes: ESA (Stress Scale for Teenagers: ESA). Sao Paulo, SP: Casa do Psicologo. 